\title{
PENGEMBANGAN MEDIA PEMBELAJARAN FISIKA BERBASIS ANIMASI FLASH TOPIK BAHASAN USAHA DAN ENERGI
}

\author{
Arif Rahman Aththibby \\ M. Barkah Salim \\ Pendidikan Fisika FKIP Universitas Muhammadiyah Metro \\ Email: aththibby@yahoo.com
}

\begin{abstract}
The use of computers as a learning medium is increasing. But there is still a bit of educators who use the computer as a medium of education facilities. Based on the research of some experts note that by using animation using flash operated by a computer, student learning outcomes improved. Therefore, it is necessary to develop media-based learning physics flash animation subject and Energy Enterprises are using Macromedia Flash 8. Media are developed based on the ADDIE development model, namely Analysis, Design, Development, Implementation, and Evaluation. The program was tested by experts in the study of physics and media experts to determine the feasibility media (program) based on predetermined criteria. After the test results obtained through the medium of learning developed worthy to serve as a medium of learning and can be used in learning.
\end{abstract}

Keywords: Media, Learning, Animations.

\section{PENDAHULUAN}

Fisika sebagai salah satu cabang IPA, mempelajari dan menganalisis secara kuantitatif gejala atau proses alam. Fisika merupakan ilmu pengetahuan yang mempelajari bagian-bagian alam dan interaksi yang ada di dalamnya. Melalui interaksi ini, ilmu fisika membantu mengungkap dan memahami tabir misteri alam semesta.

Selain itu, pelajaran fisika merupakan pelajaran yang memberikan pengetahuan tentang alam semesta untuk berlatih berpikir dan bernalar, melalui kemampuan penalaran seseorang yang terus dilatih sehingga semakin berkembang, maka orang tersebut akan bertambah daya 
pikir dan pengetahuannya (Supardi, 2012). Atas dasar inilah Fisika mutlak wajib diajarkan pada setiap siswa. Fenomena tersebut merupakan masalah yang serius dan perlu mendapatkan perhatian penuh dari semua pihak, baik pemerintah, sekolah, masyarakat/ orang tua maupun siswa itu sendiri.

Menurut Utami (2014) fisika mempelajari tentang fenomena alam pada tingkat dasar, logikanya sangat masuk akal karena sesuai dengan pengalaman kita sehari-hari, sedangkan pada tingkat lanjut fisika dapat dimanfaatkan untuk memprediksi perilaku alam atau gejala alam yang akan terjadi. Agar pembelajaran fisika lebih menarik diperlukan media pembelajaran yang lebih baik dan menarik, media pembelajaran seperti ini yang diharapkan bisa membuat siswa lebih tertarik pada materi pelajaran yang disampaikan oleh guru.

Namun dalam kenyataan saat ini, pembelajaran fisika belum bersumber pada upaya melibatkan siswa dengan gejala alam yang sedang dipelajari lewat keterlibatan tersebut agar siswa lebih mengenal fakta serta pemahaman yang lebih utuh sehingga berdampak pada peningkatan pemahaman konsep fisika pada siswa. Selain itu, fisika sebagai salah satu ilmu dasar merupakan ilmu yang menunjang perkembangan ilmu pengetahuan dan teknologi. Pada satu sisi kemajuan teknologi mempunyai dampak di berbagai bidang kehidupan, termasuk dalam bidang pendidikan. Namun pada sisi lain perkembangan ilmu pengetahuan dan teknologi tidak dapat lepas dari pendidikan.

Menurut Gagne yang dikutip dalam Sadiman (2010) menyatakan bahwa media adalah berbagai jenis komponen dalam lingkungan siswa yang dapat menarik minat siswa untuk belajar. Salah satu software yang dapat menggabungkan berbagai media seperti video, animasi, gambar, suara, dan sebagainya dengan cara yang mudah adalah Macromedia Flash 8.

Oleh karena itu, perlu dikembangkan sebuah media yang mampu membantu tugas guru agar mempermudah siswa dalam memahami suatu pelajaran. Untuk menjawab segala pernyataan dan anggapan yang timbul selama ini maka peneliti melakukan penelitian 
Arif Rahman Aththibby - Pengembangan Media Pembelajaran...

pengembangan media pembelajaran adalah metode penelitian yang fisika berbasis animasi flash topik digunakan untuk menghasilkan produk usaha dan energi. tertentu.

Model yang digunakan dalam

\section{METODE}

Penelitian ini dilakukan dengan metode Research and Development $(\mathrm{R}$ and D). Sugiyono (2011: 297) menyatakan bahwa metode penelitian dan pengembangan atau dalam bahasa inggris research and development pengembangan media ini adalah model ADDIE. Desain penelitian ini meliputi 5 tahap yaitu Analysis (analisis), Design (perencanaan), Development (produksi), Implementation (implemen-tasi), dan Evaluation

(evaluasi).

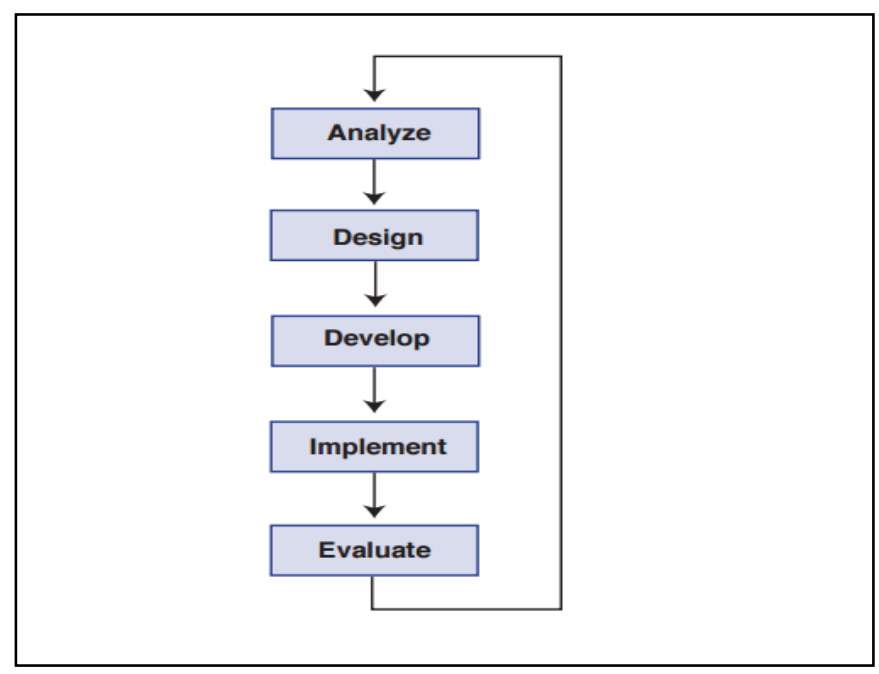

Gambar 1. Diagram model pengembangan ADDIE (Welty, 2007).

Untuk mengetahui tingkat keberhasilan pada pada penelitian pengembangan ini, digunakan angket. Angket digunakan untuk mengukur kelayakan dari media berdasarkan sisi materi maupun teknisnya. Angket menggunakan format respon empat poin dari skala Likert, dimana alternatif responnya adalah Sangat Setuju (4 point), Setuju (3 point), Kurang Setuju (2 point), dan Tidak Setuju (1 point). 
Menghitung persentase dari tiap-tiap sub variabel dengan rumus:

$$
P(s)=\frac{s}{N} \times 100 \%
$$

Dengan:

$$
\begin{array}{ll}
P(s) & =\text { persentase sub variabel } \\
S & =\text { jumlah skor tiap sub variabel } \\
N & =\text { jumlah skor maksimum }
\end{array}
$$

(Riduwan dan Akdon, 2010: 18).

\section{HASIL DAN PEMBAHASAN}

\section{Hasil Pengembangan Media}

Hasil yang diperoleh dari penelitian ini terdiri dari proses analisis kebutuhan, perancangan dan pembuatan media pembelajaran, validitas pengembangan produk dari sisi teknis dan meteri fisika. Secara ringkas data hasil penelitian dan pengembangan media pembelajaran fisika berbasis animasi flash adalah sebagai berikut:

\section{- Studi pendahuluan dan analisis}

\section{kebutuhan}

Studi pendahuluan dilakukan melalui penelusuran media yang ada dan tersedia. Dari hasil analisis kebutuhan diperoleh hasil yaitu:
1) Materi yang perlu untuk dikembangkan dalam media pembelajaran berbasis animasi komputer yaitu materi usaha, daya, energi. Hal ini karena terbatasnya media pembelajaran fisika berbasis animasi yang ada saat ini yang mengangkat topik usaha, daya dan energi.

2) Peserta didik kurang bersemangat dalam belajar fisika terlihat dari aktivitas siswa pada saat proses pembelajaran cenderung pasif dan mudah jenuh.

\section{- Rancangan awal media}

Setelah topik usaha, daya dan energi dipilih untuk disusun dalam bentuk media animasi, maka tahap selanjutnya adalah perancangan awal dan pengembangan dari media tersebut.

Berdasarkan desain atau rancangan awal dihasilkan media pembelajaran berbasis animasi komputer dengan tampilan seperti ditunjukkan pada gambar 2. 
Arif Rahman Aththibby - Pengembangan Media Pembelajaran...

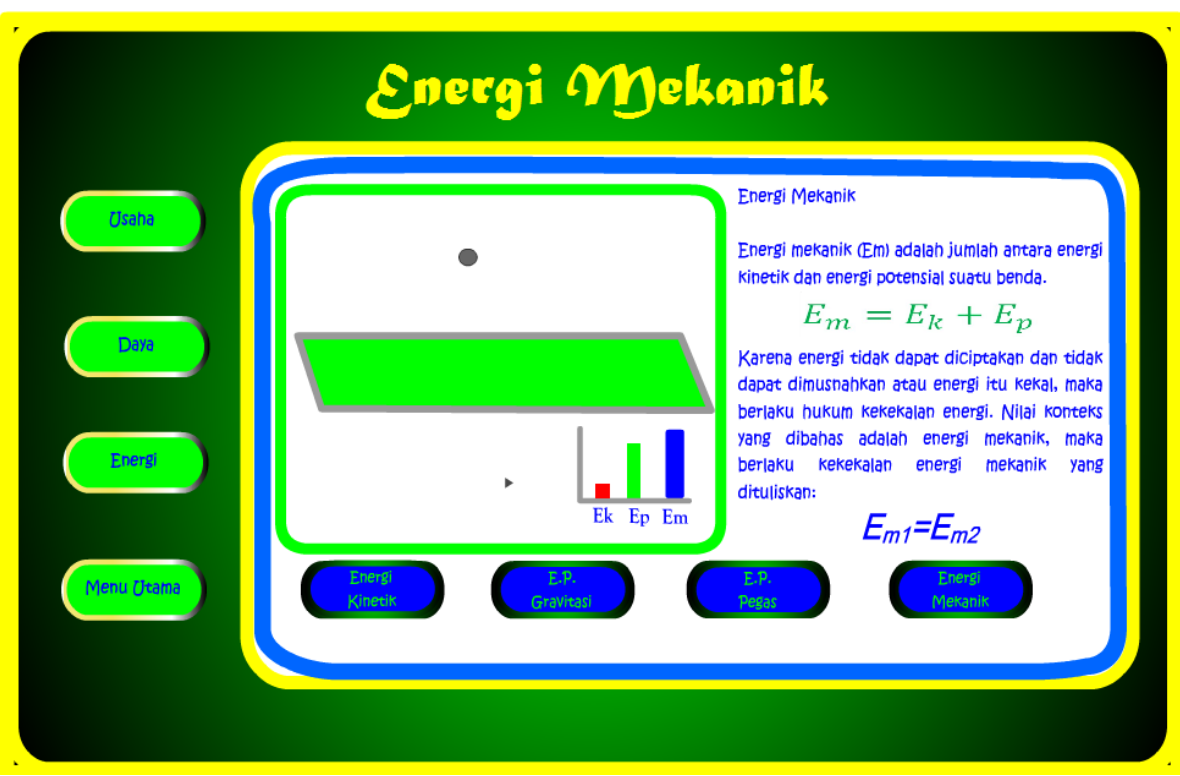

Gambar 2. Tampilan Media Pembelajaran

Tahap selanjutnya adalah

Aspek format desain berada implementasi berupa pengujian pada persentase $77,5 \%$ dengan kelayakan atau uji validasi media. kategori kuat atau layak, aspek Untuk mengetahui tingkat validitas produk maka perlu dilakukan validasi materi dan validasi teknis media.

\section{- Validasi Teknis}

Kriteria penilaian dari dosen ahli Teknis Media terdiri dari tiga aspek berupa Desain, sistem operasi, dan navigasi. Validasi dilakukan untuk memperoleh data yang akan digunakan untuk merevisi produk yang dikembangkan. Hasil validasi secara ringkas sebagai berikut: sistem operasi berada pada persentase $75 \%$ dengan kuat atau layak, dan aspek navigasi berada pada persentase $88,9 \%$ dengan kategori sangat kuat atau sangat layak. Data hasil validasi ketiga dimensi yang berupa presentase kelayakan dikonversi menjadi nilai yaitu ditunjukkan pada tabel 3 .

\section{- Validasi Materi}

Kriteria penilaian dari dosen ahli materi terdiri dari tiga aspek berupa tampilan, isi, dan bahasa. Validasi dilakukan untuk
memperoleh data yang akan 
Arif Rahman Aththibby - Pengembangan Media Pembelajaran...

digunakan untuk merevisi produk yang dikembangkan. Hasil validasi secara ringkas sebagai berikut:

Aspek format tampilan berada pada persentase $83,3 \%$ dengan kategori sangat kuat atau angat layak, aspek sistem operasi berada pada persentase $78,6 \%$ dengan kuat atau layak, dan aspek navigasi berada pada persentase $78,3 \%$ dengan kategori kuat atau layak. Data hasil validasi ketiga dimensi yang berupa presentase kelayakan dikonversi menjadi nilai yaitu ditunjukkan pada tabel 4 .

Tabel 3. Hasil Konversi Skor Validasi Teknis Media

\begin{tabular}{|r|l|r|r|r|l|l|}
\hline No & Aspek & \multicolumn{1}{|c|}{$\begin{array}{l}\text { Responden } \\
1\end{array}$} & $\begin{array}{c}\text { Responden } \\
2\end{array}$ & $\begin{array}{c}\text { Responden } \\
3\end{array}$ & $\begin{array}{l}\text { Rata- } \\
\text { rata }\end{array}$ & Kriteria \\
\hline 1 & Desain & 75 & 77.5 & 80 & 77.5 & Layak \\
\hline 2 & $\begin{array}{l}\text { Sistem } \\
\text { Operasi }\end{array}$ & 70 & 75 & 80 & 75 & Layak \\
\hline 3 & Navigasi & 79.16667 & 91.66667 & 95.83333 & 88.9 & $\begin{array}{l}\text { Sangat } \\
\text { Layak }\end{array}$ \\
\hline
\end{tabular}

Tabel 4. Hasil Konversi Skor Validasi Materi Media

\begin{tabular}{|r|l|r|r|r|l|l|}
\hline No & Aspek & \multicolumn{1}{|c|}{$\begin{array}{c}\text { Responden } \\
1\end{array}$} & $\begin{array}{c}\text { Responden } \\
2\end{array}$ & $\begin{array}{c}\text { Responden } \\
3\end{array}$ & $\begin{array}{l}\text { Rata- } \\
\text { rata }\end{array}$ & Kriteria \\
\hline 1 & Tampilan & 92.85714 & 82.14286 & 75 & 83.3 & $\begin{array}{l}\text { Sangat } \\
\text { Layak }\end{array}$ \\
\hline 2 & Isi & 75 & 82.14286 & 78.57143 & 78.6 & Layak \\
\hline 3 & Bahasa & 75 & 75 & 85 & 78.3 & Layak \\
\hline
\end{tabular}

\section{Pembahasan}

Berdasarkan hasil pengembangan media pembelajaran fisika berbasis animasi flash melalui beberapa tahap yaitu studi pendahuluan, rancangan awal, dan validasi media.

Setelah merancang media pembelajaran, tahap selanjutnya adalah melakukan validasi media 
Arif Rahman Aththibby - Pengembangan Media Pembelajaran...

pembelajaran dan penyusunan nilai 80,5\%. Hal ini menunjukkan instrumen pendukung dalam bahwa teknis dari media yang pengumpulan data. Hasil validasi dihasilkan sangat layak untuk diperoleh dari penilaian ahli media dan digunakan. Indikator dari teknis media ahli materi dapat diketahui bahwa dari yang dijadikan acuan adalah Desain, aspek teknis media ini memiliki sistem operasi, dan navigasi. kategori sangat baik karena berada pada persentase keberhasilan dengan

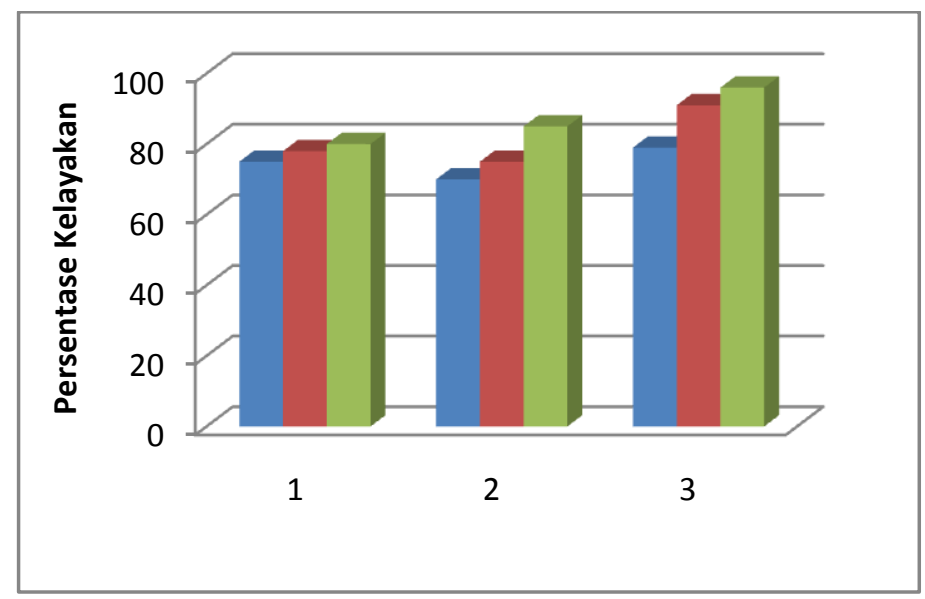

Gambar 3. Grafik Persentase Kelayakan Teknis Media

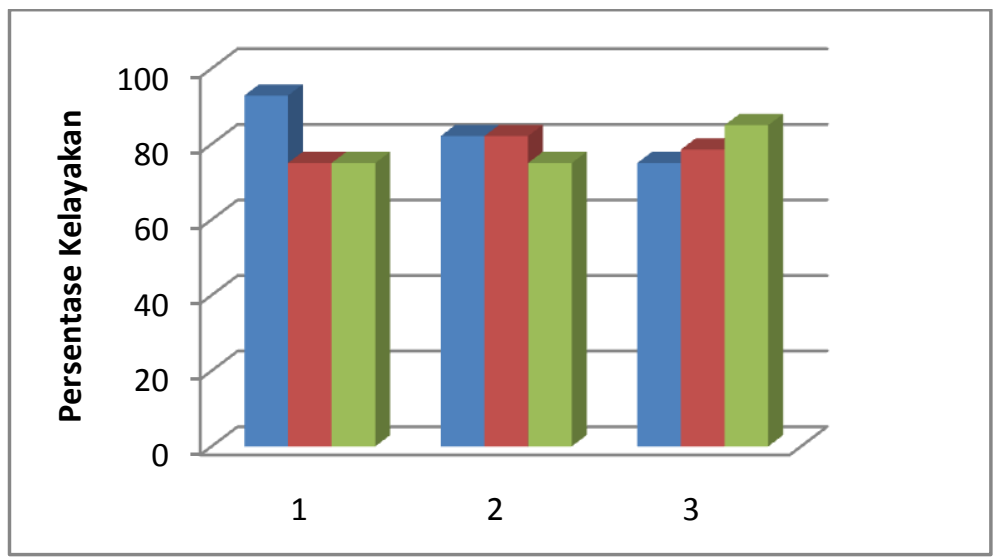

Gambar 4. Grafik Persentase Kelayakan Materi Media

Hasil validasi aspek konteks karena berada pada persentase atau kandungan materi dalam media keberhasilan dengan nilai 80,1\%. Hal ini memiliki kategori sangat baik ini menunjukkan bahwa konteks dari 
Arif Rahman Aththibby - Pengembangan Media Pembelajaran...

media yang dihasilkan sangat layak untuk digunakan. Indikator dari teknis media yang dijadikan acuan adalah format tampilan, isi dan bahasa.

\section{PENUTUP}

\section{Kesimpulan}

Berdasarkan hasil pengembangan yang telah dilakukan dapat disimpulkan sebagai berikut :

- Telah dihasilkan pengembangan media pembelajaran fisika berbasis animasi flash.

- Hasil validasi media pembelajaran fisika berbasis animasi komputer yang dikembangkan valid dan layak digunakan.

\section{Saran}

Berdasarkan hasil pengembangan dapat disarankan hal-hal sebagai berikut:

- Media pembelajaran fisika berbasis animasi flash hasil pengembangan diharapkan dapat digunakan sebagai salah satu variasi media dalam kegiatan belajar mengajar fisika bagi para guru fisika.

- Media pembelajaran fisika berbasis animasi flash yang sejenis dengan hasil pengembangan dapat dikembangkan lebih lanjut dengan materi yang berbeda dan penelitian kategori pengembangan media jenis lain yang lebih komplek.

\section{DAFTAR PUSTAKA}

Riduwan dan Akdon. 2010. Rumus dan Data dalam Analisis Statistika. Bandung: Alfabeta.

Sadiman. 2010. Media Pendidikan. Jakarta: PT Raja Grafindo Persada.

Sugiyono. 2011. Metode Peneltian Kuantitatif Kualitatif dan $R \& D$. Bandung : Penerbit Alfabeta.

Supardi U.S., dkk. 2012. Pengaruh Media Pembelajaran dan Minat Belajar Terhadap Hasil Belajar. Jurnal Formatif. Vol. 2 No.1, halaman 71-81.

Utami. 2014. Efektivitas Pemanfaatan Media Pembelajaran Animasi 
Arif Rahman Aththibby - Pengembangan Media Pembelajaran...

untuk Meningkatkan

Motivasi dan Hasil Belajar

Fisika Siswa Madarasah

Aliyah Negeri Wonosobo.

Prosiding Pertemuan Ilmiah XXVIII HFI Jateng \& DIY, (334-337). Yogyakarta, 26 April 2014.

Welty, "Strategy and Tactics for Pilot Implementation in the ADDIE Model," Journal of GXP Compliance, Vol. 12, No. 2, January 2008, pp. 1219. 